\title{
The impact of knowledge and effectiveness of educational intervention on readiness for hospital discharge and adherence to therapeutic recommendations in patients with acute coronary syndrome
}

\section{Corresponding author:}

Piotr Michalski, Department of Health Promotion, Collegium Medicum, Nicolaus Copernicus University, Bydgoszcz, Poland, e-mail: michalski.piotr@onet.eu
Medical Research Journal 2020; Volume 5, Number 2, 72-78 10.5603/MRJ.a2020.0023 Copyright ( 2020 Via Medica ISSN 2451-2591

\begin{abstract}
Introduction: ESC guidelines emphasize the importance of educating patients after acute coronary syndromes aimed at familiarizing the patient with the essence of the disease, the principles of self-control and self-care as well as actions enhancing health maintenance.

Aim: The aim of the study was to assess the impact of knowledge and effectiveness of educational intervention on readiness for discharge from the hospital and compliance with therapeutic recommendations six months after discharge.

Material and methods: The study group consisted of 218 patients ( $28.9 \%$ women and $71.1 \%$ men) aged 31 to 90 years $(63.0 \pm 11.24)$ treated with coronary angioplasty for myocardial infarction. The effectiveness of educational intervention was assessed by comparing patients' knowledge on the day of admission (1KE) and discharge from the hospital (2KE). Knowledge was assessed in 3 aspects: knowledge of symptoms, knowledge of the disease, and knowledge of prevention. Education was provided between 1KE and 2KE based on the brochure entitled "Myocardial Infarction". The level of knowledge on the day of discharge and the increase in knowledge obtained after education ( $\triangle K E)$ were referred to the level of Readiness for Hospital Discharge after Myocardial Infarction Scale (RHD-MIS) and to the level of adherence in chronic diseases scale (ACDS).

Results: As a result of the education carried out between $1 \mathrm{KE}$ and $2 \mathrm{KE}$, a significant increase in knowledge was obtained $(p<0.05)$. There was no correlation between $\triangle K E$ and RHD-MIS. However, it was shown that a higher level of knowledge at discharge (2KE) was associated with a higher RHD-MIS result $(R=$ $0.17 ; p=0.01)$. The highest impact on the RHD-MIS result was due to the level of knowledge of disease symptoms in $2 \mathrm{KE}: 75.5 \pm 19.5 \%, 76.4 \pm 21.1 \%, 85.8 \pm 16.4 \%$ for low, medium and high RHD-MIS results $(p=0.002) ; R=0.15 ; p=0.0003$. Knowledge of the disease symptoms in 2KE was associated with the patient's expectations in RHD-MIS - a higher level of knowledge was associated with higher patient expectations, respectively: $73.2 \pm 21.7 \%, 80.0 \pm 18.5 \%, 82.9 \pm 19.2$ for low, medium and high RHDMIS $(p=0.02) ; R=0.19 ; p=0.006$. There was no correlation between $\triangle K E$ or $2 K E$ and ACDS results 6 months after discharge.

Conclusions: The educational brochure is an effective tool in improving patients' level of knowledge. Better knowledge of the symptoms of coronary artery disease and myocardial infarction is associated with a higher degree of readiness for discharge from the hospital but does not affect the observance of therapeutic recommendations in the field of pharmacotherapy after 6 months.

Key words: health education, myocardial infarction, readiness for hospital discharge
\end{abstract}

Med Res J 2020; 5 (2): 72-78 


\section{Introduction}

Cardiovascular diseases, including myocardial infarction, are a serious health, social, and economic problem [1, 2]. Despite the good results in the acute phase, up to $20 \%$ of patients die within a year of having a heart attack [3]

One of the reasons for this is the insufficient degree of implementation of the therapeutic plan [4]. As indicated by WHO data in highly developed countries, only $50 \%$ of patients with chronic diseases follow the recommendations [5]. It is estimated that among patients with low levels of adherence, the risk of death is twice as high as in patients who follow the established treatment plan [6].

In order to improve the implementation of the therapeutic plan, the ESC guidelines emphasize the importance of conducting educational activities aimed at familiarizing the patient with the essence of the disease, the principles of self-control and self-care as well as actions enhancing health maintenance $[7,8]$.

The aim of the study was to assess the impact of knowledge and effectiveness of educational intervention on readiness for discharge from the hospital and compliance with therapeutic recommendations six months after discharge.

\section{Material and methods}

The presented analysis is part of a larger study entitled The impact of educational intervention on compliance with therapeutic recommendations in patients with chronic diseases, which was planned in accordance with the principles of ethics contained in the Helsinki Declaration, obtaining the consent of the Bioethical Committee at the Collegium Medicum UMK in Bydgoszcz (KB 232/2015).

The analysis included 218 patients hospitalized in the Department of Cardiology, University

Hospital No. 1 in Bydgoszcz, who met the following criteria:

- Within 48 hours of being admitted to the hospital:

- gave informed consent to participate in the study,

- completed the patient's questionnaire and a questionnaire assessing the patient's knowledge of coronary artery disease and myocardial infarction,

- adopted the author's educational brochure entitled "Myocardial infarction".

- On the day of discharge from the hospital:

- completed the Readiness for Hospital Discharge after Myocardial Infarction Scale (RHD-MIS) and the questionnaire assessing knowledge about coronary heart disease and myocardial infarction.
- After six months they answered questions regarding compliance with pharmacological recommendations (ACDS scale).

The effectiveness of educational intervention was assessed by comparing patient's knowledge of admission (1KE) and discharge from the hospital (2KE). Education was provided between $1 \mathrm{KE}$ and $2 \mathrm{KE}$ based on the brochure entitled Myocardial infarction. The level of knowledge on the day of discharge and the increase in knowledge obtained after education ( $\triangle \mathrm{KE}$ ) was related to the level of readiness to discharge from the hospital (RHD-MIS) and to the level of adherence in the field of pharmacotherapy (ACDS).

The detailed characteristics of the study group are provided in Table 1.

The questionnaire for assessing patient knowledge of coronary artery disease and myocardial infarction (KE) consisted of 20 questions. The patient received 1 point for each correct answer. The questions in the questionnaire tested knowledge in three areas: knowledge of the symptoms of coronary artery disease and myocardial infarction (questions 1-5), knowledge about the disease (questions 6-10), and knowledge about prevention (questions 11-20).

In the brochure entitled "Myocardial Infarction" contains information needed to give correct answers to all questions of the questionnaire assessing the knowledge of patients. The person submitting the brochure indicated that it contained information related to the disease and preventive measures necessary for proper functioning after leaving the hospital. In addition, standard education was carried out during the hospital stay in accordance with the procedure adopted at the clinic.

The Readiness for Hospital Discharge after Myocardial Infarction Scale (RHD-MIS) is a validated, free and publicly available tool. The questionnaire consists of 27 questions divided into 4 parts: non-scoring opinions about the disease and 3 scoring subscales assessing patient's expectations of education and patient's; knowledge (patient's self-assessment) and the information they have (objective assessment of patient's; knowledge). The patient can achieve low, medium, or high levels both as a result of the summary and in each of the subscales [9].

The Adherence in Chronic Diseases Scale (ACDS) is used to assess the level of adherence in the field of pharmacotherapy in patients with chronic diseases. It is a free, publicly available tool, validated in a group of patients treated for the acute coronary syndrome. It consists of 7 questions assessing compliance with therapeutic recommendations in the field of pharmacotherapy. The first 5 refers to behaviors directly determining adherence, while questions 6 and 7 relate to situations and views indirectly influencing the implementation of a therapeutic plan [10]. 
Table 1. The characteristics of the study group

\begin{tabular}{|c|c|c|c|}
\hline Variable & & Amount (n) & $\begin{array}{l}\text { Percentage of the total } \\
(\%)\end{array}$ \\
\hline \multirow[t]{2}{*}{ Sex } & Women & 63 & 28.9 \\
\hline & Men & 155 & 71.1 \\
\hline \multirow[t]{2}{*}{ Age } & $<65$ years & 122 & 55.96 \\
\hline & $\geq 65$ years & 96 & 44.04 \\
\hline \multirow[t]{4}{*}{ Education } & Primary education & 28 & 12.84 \\
\hline & Basic vocational education & 77 & 35.32 \\
\hline & Secondary education & 83 & 38.07 \\
\hline & Higher education & 30 & 13.76 \\
\hline \multirow[t]{4}{*}{ Employment status } & Employed & 86 & 39.45 \\
\hline & Unemployed & 14 & 6.42 \\
\hline & Pensioner & 89 & 40.83 \\
\hline & Invalid & 29 & 13.30 \\
\hline \multirow[t]{4}{*}{ Economic status } & Very good & 12 & 5.5 \\
\hline & Satisfactory & 194 & 88.99 \\
\hline & Bad & 12 & 5.5 \\
\hline & Very Bad & 0 & 0.0 \\
\hline \multirow[t]{3}{*}{ Place of residence ${ }^{\star}$} & City & 113 & 51.83 \\
\hline & Town & 49 & 21.1 \\
\hline & Village & 59 & 27.06 \\
\hline \multirow[t]{3}{*}{ Marital status } & Single & 23 & 10.55 \\
\hline & In a relationship & 166 & 76.15 \\
\hline & Widow/widower & 29 & 13.30 \\
\hline \multirow[t]{2}{*}{ Lives } & Alone & 26 & 11.93 \\
\hline & With family & 192 & 88.07 \\
\hline \multirow[t]{2}{*}{ History of CAD } & Yes & 130 & 55.62 \\
\hline & No & 88 & 40.37 \\
\hline \multirow[t]{2}{*}{ Prior hospitalization for CAD } & Yes & 100 & 45.87 \\
\hline & No & 118 & 54.13 \\
\hline \multirow[t]{2}{*}{ Prior MI } & Yes & 62 & 28.44 \\
\hline & No & 156 & 71.56 \\
\hline \multirow[t]{2}{*}{ Prior PCl } & Yes & 80 & 36.7 \\
\hline & No & 138 & 63.3 \\
\hline \multirow[t]{2}{*}{ Prior CABG } & Yes & 33 & 15.14 \\
\hline & No & 185 & 84.86 \\
\hline \multirow[t]{2}{*}{ Level of knowledge } & Sufficient & 32 & 14.68 \\
\hline & Insufficient & 186 & 85.32 \\
\hline
\end{tabular}

*City > 100000 inhabitants; Town $\leq 100000$ inhabitants 


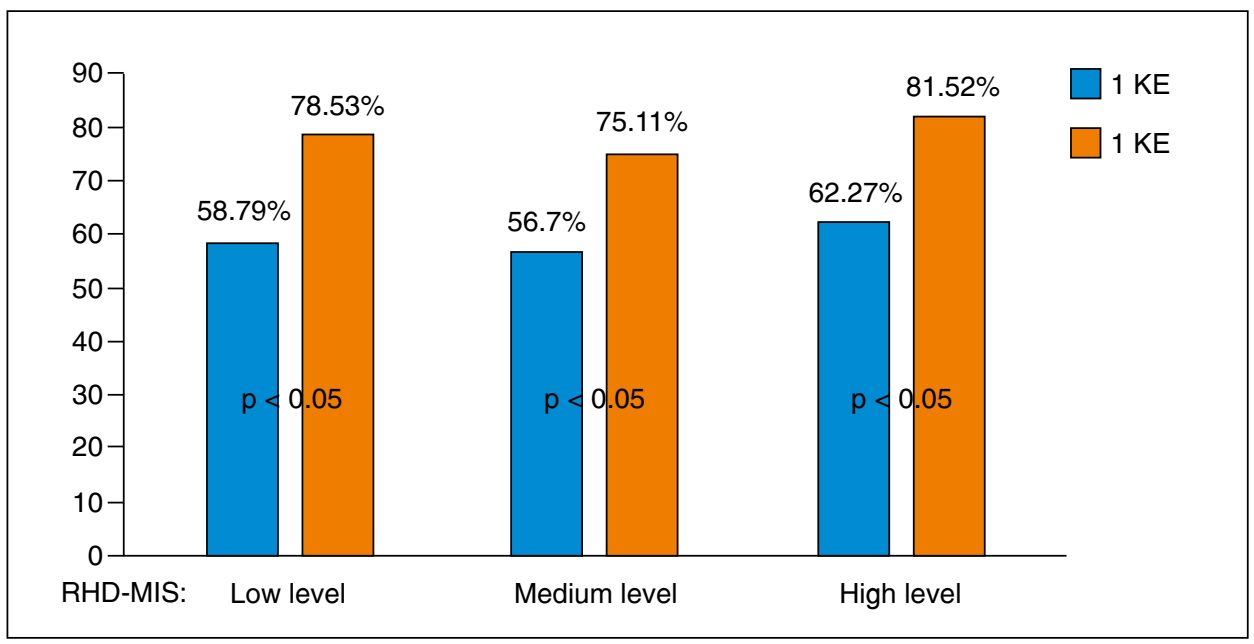

Figure 1. Comparison of the level of knowledge before education (1KE) and after educational intervention (2KE) in relation to the level of readiness for discharge (RHD-MIS)

Table 2. Relation of the results of knowledge about education (2KE) and transfer of educational intervention $(\Delta \mathrm{KE})$ to the level of improvement to discharge (RHD-MIS)

\begin{tabular}{|c|c|c|c|c|c|c|c|c|}
\hline \multirow[t]{3}{*}{ Questionnaire } & \multirow[t]{3}{*}{ Range of patients' knowledge } & \multicolumn{6}{|c|}{$\begin{array}{l}\text { Readiness from Hospital Discharge after Myocardial } \\
\text { Infarction Scale (RHD-MIS) }\end{array}$} & \multirow[t]{3}{*}{$\mathbf{P}$} \\
\hline & & \multicolumn{2}{|c|}{ Low } & \multicolumn{2}{|c|}{ Medium } & \multicolumn{2}{|c|}{ High } & \\
\hline & & Mean & SD & Mean & SD & Mean & SD & \\
\hline \multirow[t]{4}{*}{$2 K E$} & $\begin{array}{l}\text { Knowledge of signs and symptoms } \\
\text { disease }\end{array}$ & 75.52 & 19.48 & 76.38 & 21.14 & 85.76 & 16.37 & 0.002 \\
\hline & Knowledge of the disease & 87.93 & 20.84 & 81.49 & 26.60 & 90.00 & 18.97 & 0.08 \\
\hline & Knowledge of prevention & 75.34 & 15.70 & 71.28 & 17.73 & 75.15 & 16.66 & 0.28 \\
\hline & Total score & 78.53 & 12.21 & 75.11 & 15.86 & 81.52 & 12.59 & 0.03 \\
\hline \multirow[t]{4}{*}{$2 \mathrm{KE}-1 \mathrm{KE}$} & $\begin{array}{l}\text { Knowledge of signs and symptoms of } \\
\text { the disease }\end{array}$ & 16.90 & 25.63 & 22.55 & 29.80 & 26.06 & 26.71 & 0.08 \\
\hline & Knowledge of the disease & 29.60 & 32.59 & 21.49 & 36.54 & 19.39 & 28.92 & 0.49 \\
\hline & Knowledge of prevention & 17.59 & 23.86 & 14.79 & 25.89 & 15.76 & 23.54 & 0,73 \\
\hline & Total score & 19.74 & 16.47 & 18.40 & 22.37 & 19.24 & 18.17 & 0,74 \\
\hline
\end{tabular}

\section{Results}

In the analysis performed, no correlation was observed between the increase in knowledge $(\Delta \mathrm{KE})$ and the RHD-MIS level ( $R=-0.01 ; p=0.85)$ (Fig. 1, Tab. 2).

It was shown that a higher level of knowledge at discharge (2KE) was associated with a higher RHD-MIS result, although the correlation was very weak $(R=0.17$; $p=0.01$ ). The differences between the various areas of knowledge with regard to the level of RHD-MIS were not significant, except for the knowledge of the symptoms of the disease (Tab. 2).

The results of the assessment of the level of knowledge of patients after intervention using the brochure (2KE) referring to individual components of the RHDMIS questionnaire are presented in Table 3.
The resources of patients' knowledge (2KE), despite the visible trend ( $p$ for trend $=0.023$ ) and very weak positive correlation $(R=0.1445 ; p=0.0037$ ) did not differentiate between groups of patients according to the RHD-MIS level in the subscale of subjective knowledge assessment. However, a relationship between better knowledge of disease symptoms and higher self-assessment results were noted.

The objective knowledge assessments of patients (only with respect to disease symptoms) were consistent with two methods - the 2KE survey and the RHDMIS scale, which was also confirmed by correlation $(R=0.1606 ; p=0.02)$. The level of general knowledge on discharge (2KE) very weakly correlated with the results of the RHD-MIS subscale objectively assessing the knowledge of patients $(R=0.1384 ; p=0.04)$. 
Table 3. Comparison of the results of the assessment of patients' knowledge after educational intervention (2KE) in relation to the level of readiness for discharge in individual subscales of the RHD-MIS questionnaire

\begin{tabular}{|c|c|c|c|c|c|c|c|c|}
\hline \multirow[t]{3}{*}{ Questionnaire } & \multirow[t]{3}{*}{ Range of patients' knowledge } & \multicolumn{6}{|c|}{$\begin{array}{l}\text { Readiness from Hospital Discharge after Myocardial } \\
\text { Infarction Scale (RHD-MIS) }\end{array}$} & \multirow[t]{3}{*}{$\mathbf{P}$} \\
\hline & & \multicolumn{2}{|c|}{ Low } & \multicolumn{2}{|c|}{ Medium } & \multicolumn{2}{|c|}{ High } & \\
\hline & & Mean & SD & Mean & SD & Mean & SD & \\
\hline \multicolumn{9}{|c|}{ RHD-MIS - subjective assessment of patient's knowledge } \\
\hline \multirow[t]{4}{*}{$2 \mathrm{KE}$} & $\begin{array}{l}\text { Knowledge of signs and symptoms } \\
\text { of the disease }\end{array}$ & 75.00 & 21.66 & 77.63 & 19.33 & 81.94 & 18.69 & 0.08 \\
\hline & Knowledge of the disease & 86.07 & 20.86 & 89.78 & 24.24 & 85.05 & 24.05 & 0.47 \\
\hline & Knowledge of prevention & 70.71 & 17.15 & 73.39 & 16.25 & 75.15 & 17.14 & 0.16 \\
\hline & Total score & 75.63 & 14.65 & 77.80 & 13.90 & 79.32 & 14.11 & 0.18 \\
\hline \multicolumn{9}{|c|}{ RHD-MIS - objective assessment of patient's knowledge } \\
\hline \multirow[t]{4}{*}{$2 \mathrm{KE}$} & $\begin{array}{l}\text { Knowledge of signs and symptoms } \\
\text { of the disease }\end{array}$ & 72.50 & 21.76 & 80.94 & 19.00 & 81.79 & 18.00 & 0.02 \\
\hline & Knowledge of the disease & 81.79 & 27.31 & 86.04 & 21.76 & 89.29 & 21.22 & 0.20 \\
\hline & Knowledge of prevention & 72.86 & 17.76 & 72.92 & 16.09 & 75.36 & 17.78 & 0.38 \\
\hline & Total score & 75.00 & 15.95 & 78.24 & 12.77 & 80.45 & 14,69 & 0,07 \\
\hline \multicolumn{9}{|c|}{ RHD-MIS - the patient's expectations } \\
\hline \multirow[t]{4}{*}{$2 \mathrm{KE}$} & $\begin{array}{l}\text { Knowledge of signs and symptoms } \\
\text { of the disease }\end{array}$ & 73.21 & 21.67 & 80.00 & 18.52 & 82.86 & 19.23 & 0.02 \\
\hline & Knowledge of the disease & 83.21 & 24.65 & 87.74 & 22.52 & 84.64 & 23.20 & 0.43 \\
\hline & Knowledge of prevention & 72.32 & 17.27 & 73.87 & 16.88 & 74.11 & 16.93 & 0.80 \\
\hline & Total score & 75.27 & 14.88 & 78.87 & 14.13 & 78.93 & 13.58 & 0.24 \\
\hline
\end{tabular}

Patients with higher expectations (in RHD-MIS) had a higher level of knowledge about the symptoms of coronary artery disease and myocardial infarction than patients with less knowledge $(p=0.02)$, which was also confirmed by weak correlation $(R=0.1875$; $\mathrm{p}=0.0056$ )

The results of knowledge assessment on discharge (2KE) were not a determining factor for ACDS in the follow-up study six months after discharge from hospital (low ACDS: $79.02 \pm 13.93$ vs. average ACDS: $76.81 \pm 19.92$ vs. high ACDS: $79.15 \pm 15.03$; $p=0.28)$. There was also no correlation between the level of adherence and the increase in knowledge $(\Delta \mathrm{KE})$, which was respectively: $21.57 \pm 17.73,18.47 \pm 21.36$, $17.80 \pm 17.91$ for low, medium and high ACDS $(p=0.20)$.

\section{Discussion}

The patient's readiness for discharge is an important element of conditioning compliance with medical recommendations. During hospitalization, the patient's participation in the implementation of the therapeutic plan is passive, consisting in agreeing to the proposed actions, while the medical team is responsible for the implementation of this plan. After leaving the hospital, the patient takes over responsibility for the treatment process [11].

Health education is an important element of therapeutic management, affecting the understanding of the essence of the disease, helping to accept and take action to achieve the best therapeutic effects [12].

The use of an educational brochure in the study resulted in a clear, though it seems still insufficient, an increase in the level of knowledge.

The obtained results confirmed our previous observations assessing the effectiveness of using the brochure in improving knowledge in patients treated for acute coronary syndrome [13-15].

As expected, the patients' knowledge measured by the $2 \mathrm{KE}$ questionnaire was consistent with the objective assessment of knowledge on the RHD-MIS scale but was not reflected in the results of the subjective assessment of patients on this scale. The subjective assessment of knowledge made by patients is unreliable and insufficient for planning educational activities.

Self-assessment of discharge readiness carried out by Andruszkiewicz et al. [16] indicates that patients after cardiovascular incidents experience a lower level prepared for discharge in the following categories: knowledge of drug use and reasons for taking it, and 
the ability to notice symptoms/changes related to health in comparison to patients with other chronic conditions.

In turn, Piwońska et al. [17], comparing the results of two multicentre cross-sectional observational studies, showed a significant improvement in knowledge about health and risk factors for cardiovascular diseases in the WOBASZ II study (2013-2014) compared to the previously conducted WOBASZ study (2003-2005).

In our study, we showed that better knowledge of disease symptoms had the greatest impact on the overall assessment of readiness for discharge. Undoubtedly, knowledge of the symptoms of the disease, making it easier for the patient to make decisions adequate to the clinical situation, can positively influence the prognosis in the pre-hospital phase.

Previous studies have shown that the time from the onset of pain to the call of medical services in patients with acute coronary syndrome is often longer than recommended in international guidelines [18, 19]. Among factors influencing the delay of the call are older age, female gender, low level of education and lack of knowledge about the knowledge of symptoms and prevention [18].

We expected patients with low knowledge to have higher expectations of education, while the results were the opposite. Patients with a relatively high level of knowledge also had a greater need to obtain health information. It can be assumed that a higher level of knowledge was necessary to realize our own needs in many of our patients influencing their attitudes.

In the face of illness, mechanisms aimed at dealing with the problem are launched. The most beneficial are active behaviors that focus on seeking information to control and influence your illness. On the other hand, the subjective picture of the disease, inadequate to both scientific knowledge and the patient's current state, may be associated with unfavorable attitudes, such as denying, repression, anxiety, or avoidance [20].

Among patients with coronary artery disease, convictions about the disease predict health behavior [21] and involvement in the rehabilitation process [22]. In our study, we did not show that the level of knowledge of patients on the day of discharge affected compliance with therapeutic recommendations in the field of pharmacotherapy after 6 months of observation. On the other hand, another study analyzing the impact of readiness for discharge on adherence showed that an increase in the objective assessment of patients' knowledge (RHD-MIS subscale) affects a higher level of compliance [23].

A systematic review of research on educational interventions applied to cardiological patients by Ghisi et al. [24] indicates education as an element supporting the therapeutic process. It should be remembered, that therapeutic education cannot be limited only to the transfer of knowledge, but above all it should develop awareness, incline to reflection and give support in implementing the therapeutic plan [25]. Researchers emphasize the need to motivate patients as a necessary element complementing educational interventions [26].

Both our research and those previously published [27-35] suggest that the practical implementation of these guidelines has a number of limitations. It is advisable to conduct further research on the determinants of readiness for discharge and implementation of the therapeutic plan.

\section{Limitations of the study}

The study did not include the patient's mental construct, which may affect the results obtained.

\section{Conclusions}

The educational brochure is an effective tool for improving patient knowledge. Better knowledge of the symptoms of coronary artery disease and myocardial infarction is associated with a higher degree of readiness for discharge from the hospital, however, it does not affect the observance of therapeutic recommendations in the field of pharmacotherapy after 6 months.

\section{References}

1. Nichols M, Townsend N, Scarborough P, et al. Cardiovascular disease in Europe 2014: epidemiological update. Eur Heart J. 2014; 35(42) 2950-2959, doi: 10.1093/eurheartj/ehu299, indexed in Pubmed: 25139896

2. World Health Organization. Mortality and global burden of disease. http://www.who.int/gho/mortality burden disease/en/.

3. García-García C, Subirana I, Sala J, et al. Long-term prognosis of first myocardial infarction according to the electrocardiographic pattern (ST elevation myocardial infarction, non-ST elevation myocardial infarction and non-classified myocardial infarction) and revascularization procedures. Am J Cardiol. 2011; 108(8): 1061-1067, doi: 10.1016/j. amjcard.2011.06.003, indexed in Pubmed: 21791326.

4. Kubica A. Self-reported questionnaires for a comprehensive assessment of patients after acute coronary syndrome. Medical Research Journal. 2019; 4(2): 106-109, doi: 10.5603/mrj.a2019.0021.

5. Sabaté E. red.): Adherence to long-term therapies: evidence for action. World Health Organization. : Geneva.

6. Simpson SH, Eurich DT, Majumdar SR, et al. A meta-analysis of the association between adherence to drug therapy and mortality. BMJ. 2006; 333(7557): 15, doi: 10.1136/bmj.38875.675486.55, indexed in Pubmed: 16790458

7. Piepoli MF, Hoes AW, Agewal S, et al. Wytyczne ESC dotyczace prewencji chorób sercowo-naczyniowych w praktyce klinicznej w 2016 roku. Kardiol Pol 2016; 74. ; 9: 821-836, doi: 10.5603/KP.2016.0120.

8. Ibanez B, James S, Agewall S, et al. ESC Scientific Document Group. 2017 ESC Guidelines for the management of acute myocardial infarction in patients presenting with ST-segment elevation: The Task Force for the management of acute myocardial infarction in patients presenting with ST-segment elevation of the European Society of Cardiology (ESC). Eur Heart J. 2018; 39(2): 119-177, doi: 10.1093/eurheartj/ehx393, indexed in Pubmed: 28886621.

9. Buszko K, Kosobucka A, Michalski P, et al. The readiness for hospital discharge of patients after acute myocardial infarction: a new self-re- 
ported questionnaire. Medical Research Journal. 2017; 2(1): 20-28, doi: 10.5603/mrj.2017.0004

10. Buszko K, Obońska K, Michalski P, et al. The Adherence Scale in Chronic Diseases (ASCD). The power of knowledge: the key to successfu patient - health care provider cooperation. Medical Research Journal. 2016; 1(1): 37-42, doi: 10.5603/mrj.2016.0006

11. Weiss ME, Costa LL, Yakusheva O, et al. Validation of patient and nurse short forms of the Readiness for Hospital Discharge Scale and their relationship to return to the hospital. Health Serv Res. 2014 49(1): 304-317, doi: 10.1111/1475-6773.12092, indexed in Pubmed 23855675

12. Kubica A, Gruchała M, Jaguszewski M, et al. Adherence to treatment - a pivotal issue in long-term treatment of patients with cardiovascular diseases. An expert standpoint. Medical Research Journal. 2018; 2(4) 123-127, doi: 10.5603/mrj.2017.0016

13. Kubica A, et al. Kochman W., Bogdan M The influence of undergone pecutaneous coronary interventions and earlier hospitalization with myocardial infarction on the level of knowledge and the effectiveness of health education in patients with myocardial infarction. Advances in Interventional Cardiology. 2009; 5: 25-30.

14. Kubica A Kasprzak M Obońska K et al. Impact of health education on adherence to clopidogrel and clinical effectiveness of antiplatelet treatment in patients after myocardial infarction. Medical Research Journal. 2016; 3(4): 154-159, doi: 10.5603/fmc.2015.0010.

15. Michalski P, Kosobucka A, Pietrzykowski $Ł$, et al. Effectiveness of therapeutic education in patients with myocardial infarction. Medical Research Journal. 2018; 2(3): 89-96, doi: 10.5603/mrj.2017.0011.

16. Andruszkiewicz A, Kubica A, Nowik M, et al. Ocena gotowości do wypisu pacjentów z chorobami przewlekłymi. Zdrowie Publiczne i Zarzadzanie 2016; 14 : 1: 44-52, doi: 10.4467/208426270Z.16.007.5569.

17. Piwońska A, Piotrowski W, Piwoński J, et al. Cardiovascular health knowledge of the Polish population. Comparison of two national multi-centre health surveys: WOBASZ and WOBASZ II. Kardiol Pol. 2017: 75(7): 711-719, doi: 10.5603/KP.a2017.0070, indexed in Pubmed: 28394004

18. Wechkunanukul K, Grantham H, Clark RA. Global review of delay time in seeking medical care for chest pain: An integrative literature review. Aust Crit Care. 2017; 30(1): 13-20, doi: 10.1016/j.aucc.2016.04.002, indexed in Pubmed: 27117387.

19. Makam RP, Erskine N, Yarzebski J, et al. Decade Long Trends (20012011) in Duration of Pre-Hospital Delay Among Elderly Patients Hospitalized for an Acute Myocardial Infarction. J Am Heart Assoc 2016; 5(4): e002664, doi: 10.1161/JAHA.115.002664, indexed in Pubmed: 27101833

20. Leksowska A. Jaworska I., Gorczyca P.: Choroba somatyczna jako wyzwanie adaptacyjne dla człowieka. Fiolia Cardiologica Excerpta. 2011: 6(4): 244-248

21. Scharloo M, Kaptein AA, Weinman J, et al. Illness perceptions, coping and functioning in patients with rheumatoid arthritis, chronic obstructive pulmonary disease and psoriasis. Journal of Psychosomatic Research. 1998; 44(5): 573-585, doi: 10.1016/s0022-3999(97)00254-7.

22. Whitmarsh A, Koutantji M, Sidell K. Illness perceptions, mood and coping in predicting attendance at cardiac rehabilitation. $\mathrm{Br} \mathrm{J}$ Health Psychol. 2003; 8(Pt 2): 209-221, doi: 10.1348/135910703321649178, indexed in Pubmed: 12804334.

23. Kosobucka A, Michalski P, Pietrzykowski $Ł$, et al. The impact of readiness to discharge from hospital on adherence to treatment in patients after myocardial infarction. Cardiol J. 2020 [Epub ahead of print], doi: 10.5603/CJ.a2020.0005, indexed in Pubmed: 32037501

24. Ghisi GL, Abdallah F, Grace SL, et al. A systematic review of patient education in cardiac patients: do they increase knowledge and promote health behavior change? Patient Educ Couns. 2014; 95(2): 160-174, doi: 10.1016/j.pec.2014.01.012, indexed in Pubmed: 24529720

25. WHO Regional Office for Europe. Therapeutic patient education. Continuing programmes for health care providers in the field of prevention of chronic disease. Raport of a WHO Working Group. Copenhagen 1998. http://www.euro.who.int/document/e63674.pdf (dostęp z dnia 16. 05. ; 2019.

26. Kubica A, Bączkowska A. Rationale for motivational interventions as a pivotal element of multilevel educational and motivational project (MEDMOTION). Fola Cardiologica 2020; 15. ; 1: 6-10, doi: 10.5603/FC.2020.0003.

27. Pinnarelli L, Mayer F, Bauleo L, et al. Adherence to antiplatelet therapy after percutaneous coronary intervention: a population study in a region of Italy. J Cardiovasc Med (Hagerstown). 2015; 16(3): 230-237, doi: 10.2459/JCM.0000000000000070, indexed in Pubmed: 25325532.

28. Latry P, Martin-Latry K, Lafitte M, et al. Dual antiplatelet therapy after myocardial infarction and percutaneous coronary intervention: analysis of patient adherence using a French health insurance reimbursement database. Eurolntervention. 2012; 7(12): 1413-1419, doi: 10.4244/EIJV7I12A221, indexed in Pubmed: 22522552.

29. De Backer G, De Bacquer D, Rydén L, et al. EUROASPIRE investigators. Lifestyle and risk factor management in people at high cardiovascular risk from Bulgaria, Croatia, Poland, Romania and the United Kingdom who participated in both the EUROASPIRE III and IV primary care surveys. Eur J Prev Cardiol. 2016; 23(15): 1618-1627, doi: 10.1177/2047487316645474, indexed in Pubmed: 27084894

30. Kotseva K, De Backer G, De Bacquer D, et al. EUROASPIRE Investigators*. Lifestyle and impact on cardiovascular risk factor control in coronary patients across 27 countries: Results from the European Society of Cardiology ESC-EORP EUROASPIRE V registry. Eur J Prev Cardiol. 2019; 26(8): 824-835, doi: 10.1177/2047487318825350, indexed in Pubmed: 30739508

31. Kubica A, Kosobucka A Fabiszak T et al. Assessment of adherence to medication in patients after myocardial infarction treated with percutaneous coronary intervention. Is there a place for newself-reported questionnaires? Curr Med Res Opin. 2019; 35(2): 341-349, doi: 10.1080/03007995.2018.1510385, indexed in Pubmed: 30091642.

32. Kubica A, Kosobucka A, Michalski P, et al. The Adherence in Chronic Diseases Scale - a new tool to monitor implementation of a treatment plan. Folia Cardiol. 2017; 12(1): 19-26, doi: 10.5603/FC.a2016.0105.

33. Kubica A, Obońska K, Kasprzak M, et al. Prediction of high risk of non-adherence to antiplatelet treatment. Kardiol Pol. 2016; 74(1): 61-67, doi: 10.5603/KP.a2015.0117, indexed in Pubmed: 26101025.

34. Kubica A, Obońska K, Fabiszak T, et al. Adherence to antiplatelet treatment with P2Y12 receptor inhibitors. Is there anything we can do to improve it? A systematic review of randomized trials. Curr Med Res Opin. 2016; 32(8): 1441-1451, doi: 10.1080/03007995.2016.1182901, indexed in Pubmed: 27112628.

35. Kubica A, Kasprzak M, Obońska K, et al. Discrepancies in assessment of adherence to antiplatelet treatment after myocardial infarction. Pharmacology. 2015; 95(1-2): 50-58, doi: 10.1159/000371392, indexed in Pubmed: 25592409. 